Infant mortality

\section{Infant mortality is not an adequate summary measure of population health}

\section{D Mathers, J A Salomon, C J L Murray}

Measuring the quantity of interest

T he World Health Organisation (WHO) annually reports infant mortality rates (IMR), child mortality rates, adult mortality rates, average life expectancies, and healthy life expectancies for all 191 member states. ${ }^{12}$ IMR correlates highly with HALE across these 191 member states in $2000 \quad(r=0.93)$. Reidpath and Allotey argue that IMR is an acceptable proxy measure of population health because of this high correlation. $^{3}$

Inspection of the country specific estimates of HALE and IMR reveals that, despite the high correlation, there are substantial variations both in adult mortality and in the average loss of full health at any given level of IMR. In the nine countries with an IMR in the range of 6-7 per 1000, for example, there is a range of 71 to 80 in life expectancy at birth and a range of $10 \%$ to $15 \%$ in the proportion of total life expectancy lost through living in years of less than full health. As a more specific example, females in India and Zimbabwe both had IMRs close to 63 per 1000 in the year 2000 , but the life expectancies at birth for these two populations were 46.0, and 62.7 years, respectively.

Correlation of variables in itself is no argument to use one as a proxy for the other in scientific analyses. For example, breast cancer mortality rates in women correlate highly with age $(r=0.95$ for Australia, New Zealand, and Japan using five year age groups). ${ }^{4}$ Should we stop monitoring breast cancer mortality and monitor female age instead to determine if prevention programmes are effective? Healthy life expectancy has a correlation of 0.76 with average telephone lines per capita across 164 countries. $^{5}$ At what level of correlation should we cease to measure healthy life expectancy and focus instead on telephone lines? For

The acronym for healthy life expectancy was changed from DALE to HALE in the World Health Report 2001.' that matter, female IMR correlates very highly with male IMR across the 191 WHO member states in $2000(r=0.996)$; by the argument of Reidpath and Allotey, we could use male IMR as a good indicator for women's health.

Although there may a high correlation between infant mortality and other components of health cross sectionally, time trends may differ substantially, and this is of great importance for the evaluation of health systems and policy. In Australia, the Aboriginal IMR has declined 50\% faster than non-Aboriginal IMR over the past 20 years, at the same time that the gap in total life expectancy at birth has widened from 16 years to 20 years. ${ }^{67}$ In sub-Saharan Africa, infant mortality rates have declined by $17 \%$ over the past decade, whereas adult mortality (the probability of dying between ages 15 and 60 ) has increased by 37\% reflecting the devastating impact of the AIDS epidemic. ${ }^{18}$ Clearly IMR is not an adequate summary measure for monitoring trends and differentials in population health.

Good science entails measuring the quantity of interest rather than using a proxy with an additional error term that is unknown (until we measure the quantity of interest). Without measuring average levels of population health, the most important outcome of the health system, it is impossible to assess whether health policies are working-whether levels of health are improving and inequalities are being reduced. Health policy is not aimed only at reducing mortality. Substantial resources are devoted to reducing the incidence and prevalence of conditions that cause ill health but not death, and to reducing their impact on people's lives. So it is important to capture both fatal and nonfatal health outcomes in any summary measure of population health (SMPH).

Broad interest and use of SMPH in the policy arena ${ }^{9-11}$ demonstrates the recognition of their value at the practical level for monitoring population health. Mortality indicators are not adequate for this purpose, given the considerable policy interest for many populations as to whether-and to what extent-gains in life expectancy have been accompanied by improvements in health status. ${ }^{12}$ The World Health Reports use healthy life expectancy as a summary measure of the level of population health in member countries in order to provide a comparative assessment of average levels of health, supported by more detailed estimates of mortality and burden of disease by age, sex, and cause. Over time, successive reporting on healthy life expectancy will provide evidence of progress towards achieving global goals for improving health, fatal and non-fatal, for people of all ages.

J Epidemiol Community Health 2003;57:319

\section{Authors' affiliations}

C D Mathers, J A Salomon, C J L Murray, Evidence and Information for Policy, World Health Organisation, 1211 Geneva 27 . Switzerland

Correspondence to: $\operatorname{Dr}$ C D Mathers; mathersc@who.int

\section{REFERENCES}

1 World Health Organiation. The World Health Report 2001. Mental health: new understanding, new hope. Geneva: WHO, 2001

2 Lopez AD, Ahmad OB, Guillot M, et al. World mortality in 2000: life tables for 191 countries. Geneva: WHO, 2002

3 Reidpath DD, Allotey P. Infant mortality rate as an indicator of population health. $J$ Epidemiol Community Health 2003:57:344-6.

4 Mathers CD, Stein C, Tomijima N, et al. Global burden of disease 2000: version 2 methods and results. Geneva: WHO (GPE Discussion Paper no 50), 2002.

5 World Bank. World development indicators [CD-ROM]. Washington, DC: IBRD, World Bank, 1999

6 Mathers CD, Douglas RM. Measuring progress in population health and wellbeing. In: Eckersley R, ed. Measuring progress: Is life getting better? Collingwood, Victoria, CSIRO Publishing, 1998:125-155

7 Australian Institute of Health and Welfare. Australia's health 2002. Canberra: AlHW, 2002.

8 Murray CJL, Lopez AD, eds. The global burden of disease: a comprehensive assessment of mortality and disability from diseases, injuries and risk factors in 1990 and projected to 2020. 1 st edn. Cambridge: Harvard University Press, 1996.

9 Murray CJL, Frenk J. World Health Report 2000: a step towards evidence-based health policy. Lancet 2001;357:1698-700.

10 Field MJ, Gold GM, eds. Summarizing population health: directions for the development and application of population metrics. Washington, DC: National Academy Press, 1998.

11 Murray CJL, Salomon JA, Mathers CD, et al, eds. Summary measures of population health! concepts, ethics, measurement and applications. Geneva: WHO, 2002

12 van de Water HP, Perenboom RJ, Boshuizen HC. Policy relevance of the health expectancy indicator: an inventory of European Union countries. Health Policy 1996;36: 1 17-29. 